\title{
Paralleling of Buck Converters for DC Microgrid Operation
}

\author{
Daniel Zammit, Cyril Spiteri Staines, Maurice Apap, Alexander Micallef \\ Department of Industrial Electrical Power Conversion \\ University of Malta \\ Malta \\ daniel.zammit@um.edu.mt
}

\begin{abstract}
This paper presents the controller design of paralleled Buck converters using Droop Control to obtain common load sharing for DC Microgrid operation. Proportional Integral (PI) controllers are used to provide nested current and voltage control of the Buck converters. Droop control is applied to obtain load sharing between the paralleled converters. Then, a voltage restoration loop is applied utilizing another PI controller to restore the desired voltage in the dc microgrid, correcting any voltage deviations caused by the droop loop. The operation of the controllers is tested by simulating two paralleled Buck converters operated in the continuous current mode while sharing a common resistive load.
\end{abstract}

Keywords—proportional integral; droop; dc microgrid; voltage restoration; parallel operation

\section{Introduction}

A microgrid is the integration of a number of distributed power generation systems, energy storage systems as well as consumer loads to form a self sustainable electrical grid system. Microgrids can be AC or DC or a combination of both. This selection would depend on the different applications and utilisation of the microgrid. The concept of the microgrid has gained popularity due to the increasing number of distributed power generation systems, many of which are renewable energy sources. Another attractive aspect of the microgrid is the ability to operate both in gridconnected mode as well as in islanded mode. In gridconnected mode the microgrid is connected through a coupling point to the electrical grid, while in islanded mode the microgrid is operated in an autonomous way disconnected from the electrical grid. The islanded mode provides the advantage of isolated operation in case of failure in the electrical grid. Fig. 1 shows an example of a DC microgrid.

Different scenarios call for different AC or DC microgrid configurations, but the DC microgrid concept is highly being researched due to the number of advantages it can offer. A DC microgrid can offer several advantages, namely; lower conversion losses due to less conversion stages (dc to ac and vis-versa), no synchronisation, phase or frequency issues (as present in AC microgrids), and also independence from voltage sags, dips, and other power quality issues occurring on the electrical AC grid side. These DC microgrid advantages are an attraction for usage with consumer electronics (which mainly operate with DC), electric vehicles, telecommunication equipment, military equipment and also offer an attractive solution for electricity provision in rural areas. Currently, research is being carried out to optimize and facilitate the connection of renewable energy sources like photovoltaic systems and wind turbine systems, as well as energy storage systems like batteries and super-capacitors with various loads [1].

A lot of research is being performed on DC microgrids since there is still a lot to be studied on various aspects like modelling, control design and stability testing of the various converters and systems integrated in the DC microgrid, as well as on energy storage and energy management within the DC microgrid [1-10]. In [2] a hierarchical control system for microgrids was proposed consisting of three levels; primary control based on droop, secondary control to restore deviations caused by the primary control, and tertiary control to manage the power flow between the microgrid and external electrical distribution systems. In [1] and [3] the control is extended to multiple DC microgrids connected together, to regulate power flow among the microgrids as well as the overall stability of the connected systems.

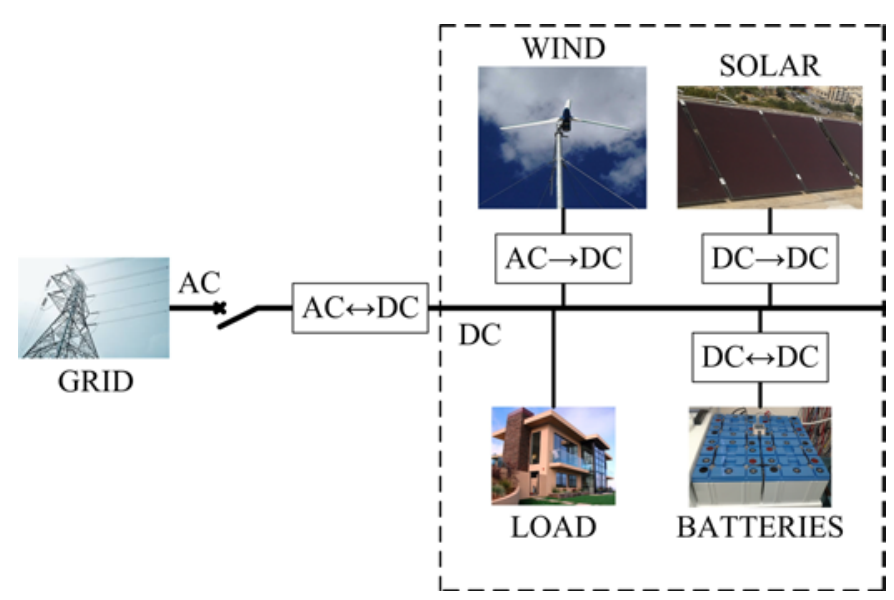

Fig. 1. DC Microgrid 
This paper presents a concise but clear procedure to design the current and voltage nested loops using Proportional Integral (PI) controllers, to control the inductor current and the output voltage of a Buck converter. The droop method is utilized to obtain load sharing between the paralleled converters. The paper also includes the design of another outer loop utilizing a PI controller for voltage restoration in the DC microgrid. The result of the design will be shown by simulating two paralleled Buck converters operated in continuous conduction mode (CCM) connected to a shared resistive load.

\section{Buck Converter Model and Control System}

\section{A. Buck Converter}

The Buck Converter shown in Fig. 2 is a switching converter that produces a lower average output voltage $\left(V_{o}\right)$ than the dc input voltage $\left(V_{i n}\right)$.

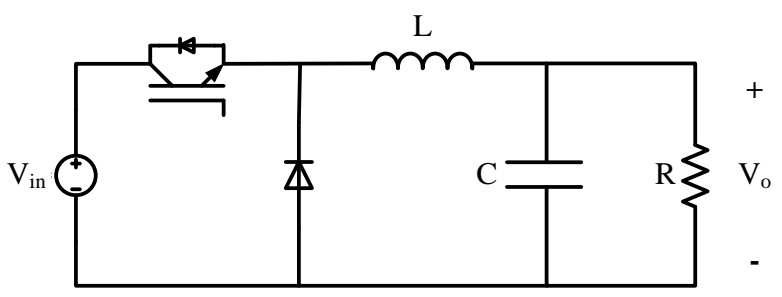

Fig. 2. Buck Converter

For the Buck converter the voltage conversion ratio of the output voltage to the input voltage $(M(D))$, which is a function of the Duty Cycle $(D)$, is given by:

$$
M(D)=\frac{V_{o}}{V_{\text {in }}}=D
$$

The inductor $(L)$ value can be found by:

$$
L=\frac{\left(V_{\text {in }}-V_{o}\right) D}{2 \Delta i_{L} f_{S}}
$$

where $\Delta i_{L}$ is the desired inductor current peak ripple and $f_{s}$ is the switching frequency of the Buck converter.

The capacitor $(C)$ value can be found by:

$$
C=\frac{\Delta i_{L}}{8 \Delta v_{o} f_{s}}
$$

where $\Delta v_{o}$ is the desired output voltage peak ripple.

\section{B. Buck Converter Model}

The linearized small signal equivalent circuit for the Buck converter including the inductor resistance $\left(R_{L}\right)$ and the capacitor resistance $\left(R_{c}\right)$ is shown in Fig. 3.

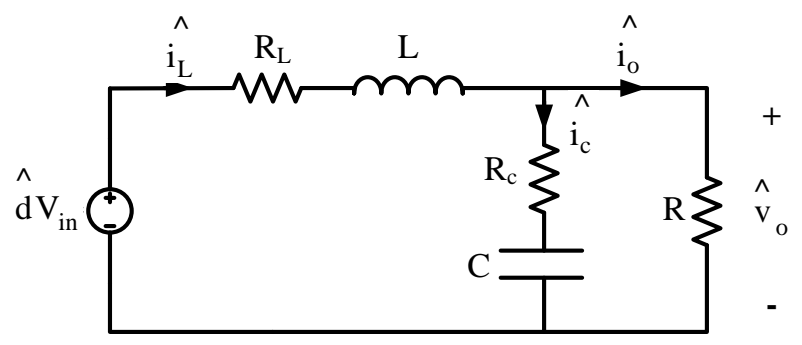

Fig. 3. Buck Converter Small Signal Equivalent Circuit

The linearized small signal mathematical model of the Buck converter is given by (4) and (5).

$$
L \frac{d \hat{i}_{L}(t)}{d t}=\hat{d} V_{\text {in }}-\hat{i}_{L}(t) R_{L}-\hat{v}_{o}(t)
$$

$\hat{i}_{C}(t)=C \frac{d \hat{v}_{C}(t)}{d t}=\hat{i}_{L}(t)-\frac{\hat{v}_{O}(t)}{R}$

where $\hat{i}_{L}(t), \hat{i}_{c}(t), \hat{d}, \hat{v}_{o}(t)$ and $\hat{v}_{c}(t)$ are small ac variations around the quiescent values for the inductor current, capacitor current, duty cycle, output voltage and capacitor voltage, respectively.

By transforming the mathematical model equations to the s-domain and considering that the capacitor is large enough to offer good decoupling for dc values, the duty cycle to the inductor current and the inductor current to the output voltage transfer functions can be given by:

$G_{i d}(s)=\frac{\hat{i}_{L}(s)}{\hat{d}}=\frac{V_{i n}}{s L+R_{L}}$

$G_{v i}(s)=\frac{\hat{v}_{O}(s)}{\hat{i}_{L}(s)}=\frac{1+s C R_{C}}{s C}$

\section{Control System Model}

Fig. 4 shows the block diagram of the control system including the droop loop. This control system is referred to as primary control in [2]. The control system consists of two nested PI controllers, one for the current and one for the voltage. The inner current control loop should be faster than the outer voltage control loop to minimize interaction between the two loops and therefore prevent instability. 
The current and voltage PI controllers, $C_{i}(s)$ and $C_{v}(s)$, respectively, are of the form:

$$
C(s)=K_{p}+\frac{K_{I}}{s}
$$

where, $K_{P}$ is the Proportional Gain term and $K_{I}$ is the Integral term.

The plant transfer function $P_{i}(s)$ for the current PI controller is obtained by:

$P_{i}(s)=T_{\text {mod }} \times G_{i d}(s)$

where, $T_{\text {mod }}$ is the transfer function representing the pulse width modulation stage.

The pulse width modulation stage produces the duty cycle $d$ that is proportional to the control voltage $v_{c}$. The pulse width modulator makes a comparison between the control voltage $v_{c}$ and a sawtooth waveform with a peak to peak amplitude $V_{m}$. The value for $V_{m}$ is selected by the designer. The frequency of the sawtooth waveform corresponds to the desired converter switching frequency $f_{s}$. This comparison is used to determine the switching on/off of the converter switch. The pulse width modulation stage can be modelled by the transfer function $T_{\text {mod }}$ given by:

$$
T_{\text {mod }}=\frac{1}{V_{m}}
$$

The plant transfer function $P_{v}(s)$ for the voltage PI controller is obtained by:

$$
P_{v}(s)=\frac{C_{i}(s) P_{i}(s)}{1+C_{i}(s) P_{i}(s)} \times G_{v i}(s)
$$

To connect two or more converters in parallel sharing a common load the droop method is used. This prevents any circulating current between the converters in case there is any difference in the output voltages. The droop method prevents circulating currents between converters by adjusting the voltage reference provided to the voltage and current control loops. This control method is applied by inserting an additional loop with a virtual resistance $R_{\text {droop }}$ as shown in Fig. 4 . The output voltage $v_{o}$ can be expressed as:

$v_{o}=V_{\text {ref }}-R_{\text {droop }} i_{L}$

where, $V_{\text {ref }}$ is the output voltage reference at no load, and $i_{L}$ is the inductor current (or output current $i_{o}$, depending on the current sensed and utilised in the control loop). using:

The value for the virtual resistance can be calculated

$R_{\text {droop }}=\frac{\varepsilon_{V}}{i_{O \_ \text {max }}}$

where, $\varepsilon_{v}$ is the maximum permissible voltage deviation and $i_{O_{-} \max }$ is the maximum output current.

The droop control loop permits sharing of a common load between paralleled converters but causes a load dependent output voltage deviation. The voltage deviation problem can be solved by the application of another controller which restores the microgrid voltage to the desired level. This controller will form another outer control loop common to all the converters/sources in the microgrid. In this control loop the microgrid voltage will be compared with the desired voltage, and the PI compensator of the loop will generate the value needed for correct voltage restoration required for the primary control system of each converter in the microgrid. This control stage is identified as secondary control in [2]. Fig. 5 shows the block diagram of the Voltage Restoration Control Loop which is connected to all the converters making up the DC microgrid.

The voltage restoration PI controller $C_{\text {res }}$ is of the form shown in (8). The demand value of the voltage restoration loop $V_{\text {maref }}$ is set to the desired DC microgrid voltage. The actual DC bus microgrid voltage $V_{m g}$ is measured and fed back as shown in Fig. 5. This controller processes the difference between the demanded and actual voltage values to generate the required restoration voltage $V_{\text {res }} . V_{\text {res }}$ is fed to the control systems of all the converters to correct the DC bus voltage. The value of $V_{\text {res }}$ should be restricted within limits to prevent it from exceeding the maximum allowed voltage deviation.

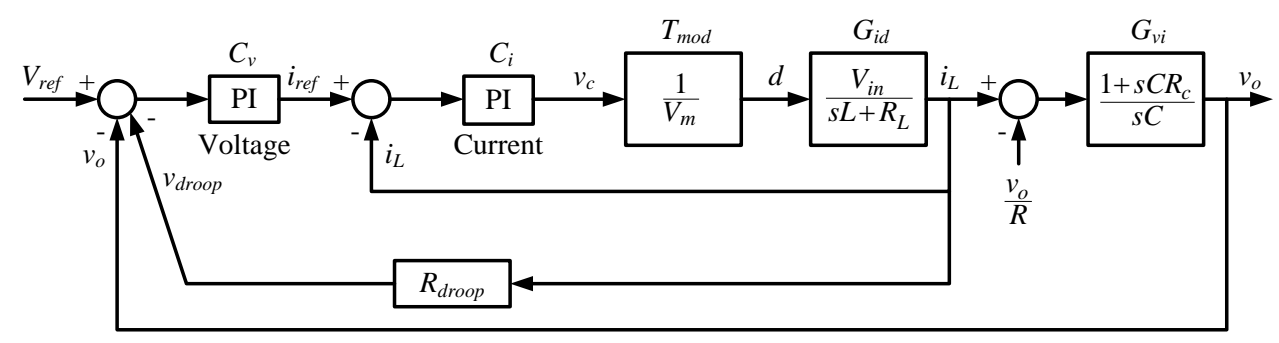

Fig. 4. Block Diagram of the Control System with Current and Voltage Control including the Droop Loop 


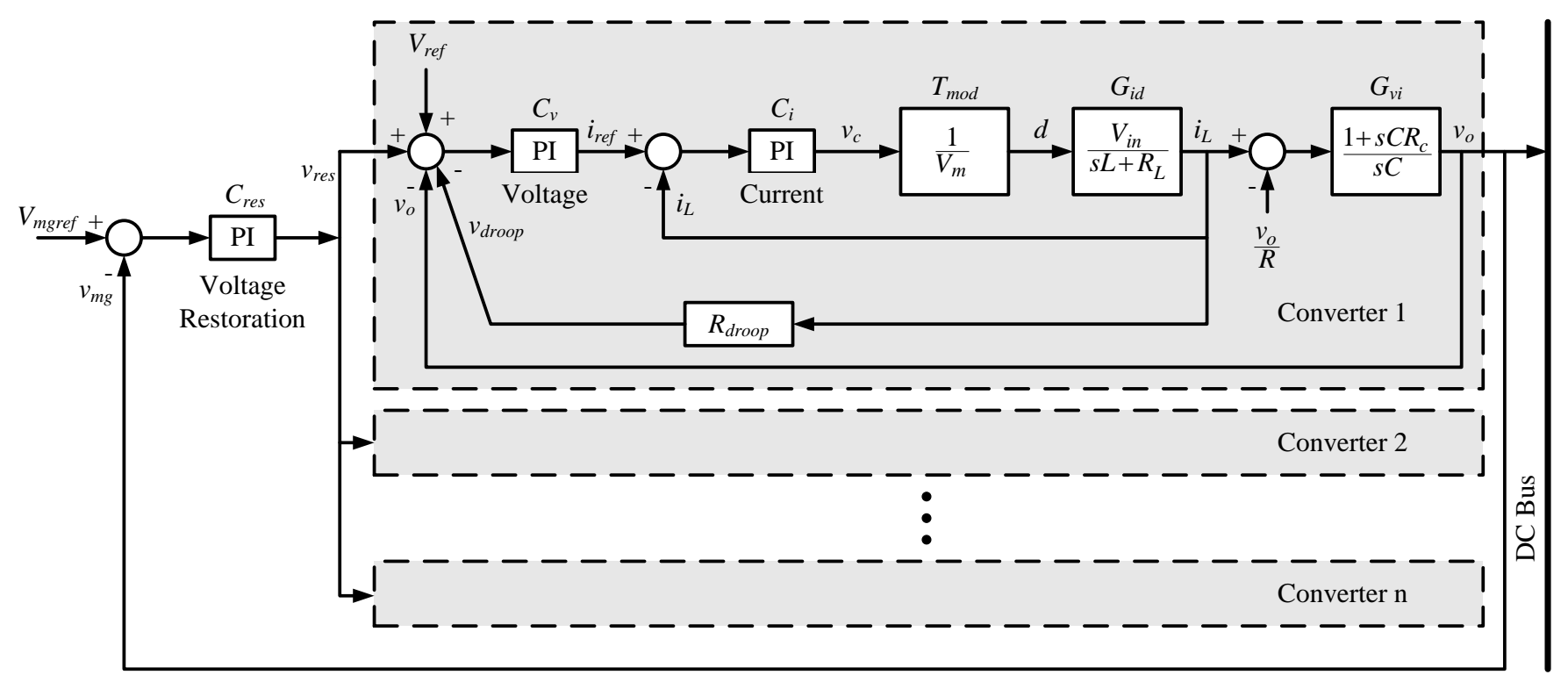

Fig. 5. Block Diagram of the Voltage Restoration Control Loop

The output voltage $v_{o}$ equation has to be modified to include this voltage restoration voltage as follows:

$v_{o}=V_{\text {ref }}+V_{\text {res }}-R_{\text {droop }} i_{L}$

The plant transfer function $P_{\text {res }}(s)$ for the voltage restoration PI controller is obtained by:

$$
P_{\text {res }}(s)=\frac{C_{v}(s) P_{v}(s)}{1+C_{v}(s) P_{v}(s)\left(1+\frac{R_{d r o o p}}{G_{v i}(s)}\right)}
$$

\section{Design of Buck Converter and Control System}

The design of the Buck converter as shown in Fig. 2 was done using (1), (2) and (3) to find the duty cycle $D$, the inductor $L$ and the capacitor $C$, respectively. The predefined set parameters and the calculated values are shown in Table 1. The inductor resistance $R_{L}$ and the equivalent series resistance (ESR) of the capacitor $R_{c}$ were taken from actual inductor and capacitor data.

The droop loop resistance was calculated using (13). The maximum percentage voltage deviation was taken to be $1 \%$ of the output voltage, thus obtaining a droop loop resistance of $0.0093 \Omega$. Transfer functions (9), (11) and (15) were used to design the current, voltage and voltage restoration PI controllers, respectively, using SISO Tool in Matlab. The value for $V_{m}$ was selected to be $100 \mathrm{~V}$, a voltage value which is equal (or can be selected higher) than the expected dc voltage of the energy source. The values for the Proportional Gain term $K_{P}$ and the Integral term $K_{I}$ for each PI controller are listed in Table 2. The bandwidths for the current, voltage and voltage restoration closed loops obtained are $495 \mathrm{~Hz}, 51 \mathrm{~Hz}$ and $0.01 \mathrm{~Hz}$, respectively.

TABLE I. BUCK CONVERTER PARAMETERS

\begin{tabular}{|l|c|}
\hline \multicolumn{2}{|c|}{ Set Parameters } \\
\hline Input Voltage $V_{\text {in }}$ & $100 \mathrm{~V}$ \\
\hline Output Voltage $V_{o}$ & $48 \mathrm{~V}$ \\
\hline Switching Frequency $f_{s}$ & $10 \mathrm{kHz}$ \\
\hline Converter Power $P$ & $2.5 \mathrm{~kW}$ \\
\hline $\begin{array}{l}\text { Inductor current peak to peak percentage ripple } \\
2 \Delta i_{L}\end{array}$ & $10 \%$ \\
\hline Output voltage peak percentage ripple $\Delta v_{o}$ & $0.5 \%$ \\
\hline Inductor Resistance $R_{L}$ & $0.002 \Omega$ \\
\hline ESR of Capacitor $R_{C}$ & $0.03 \Omega$ \\
\hline \multicolumn{2}{|c}{ Calculated Values } \\
\hline Duty Cycle $D$ & 0.48 \\
\hline Inductor $L$ & $0.479 \mathrm{mH}$ \\
\hline Capacitor $C$ & $271.25 \mu \mathrm{F}$ \\
\hline
\end{tabular}

TABLE II. PI CONTROLLERS VALUES

\begin{tabular}{|l|c|}
\hline Current PI $K_{P}$ & 1.144 \\
\hline Current PI $K_{I}$ & 880 \\
\hline Voltage PI $K_{P}$ & 0.0644 \\
\hline Voltage PI $K_{I}$ & 4.6 \\
\hline Voltage Restoration PI $K_{P}$ & 0.00102 \\
\hline Voltage Restoration PI $K_{I}$ & 0.06 \\
\hline
\end{tabular}




\section{Simulation}

The two Buck converters with the previously designed parameters and values were modelled and simulated using Matlab/Simulink. The two converters were connected in parallel and share a common resistive load. The droop loop of each converter permitted sharing of the load, and the voltage restoration controller was used to restore the microgrid bus voltage to the required 48V. Fig. 6 shows the two paralleled Buck converters and the voltage restoration control system. Fig. 7 and Fig. 8 show the control system and Buck converter modelled in Simulink, respectively.

Simulations were performed with the paralleled Buck converters to test the load sharing performance at start up and also with a step change in load. In the first simulation the start up dynamics of the converters were tested. A common resistive load of $0.4608 \Omega$ was connected to the output of the two $2.5 \mathrm{~kW}$ converters to obtain full load operation. In the second simulation the common resistive load was changed to $0.553 \Omega$, a change of approximately $20 \%$, at 1 second and changed back to $0.4608 \Omega$ at 3 seconds.
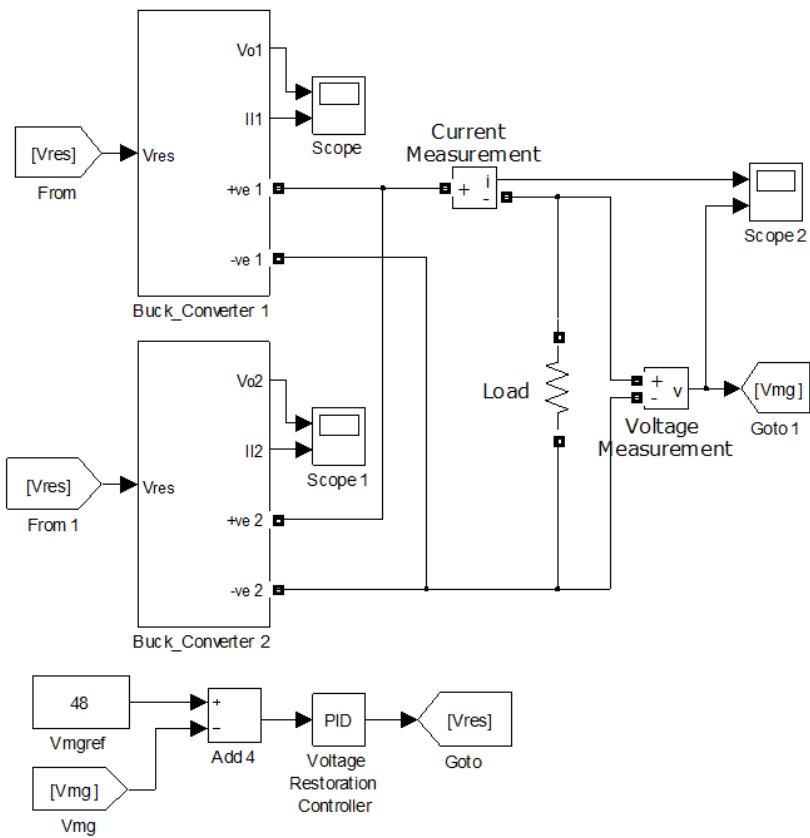

Fig. 6. Paralleled Buck Converters and the Voltage Restoration Control Loop

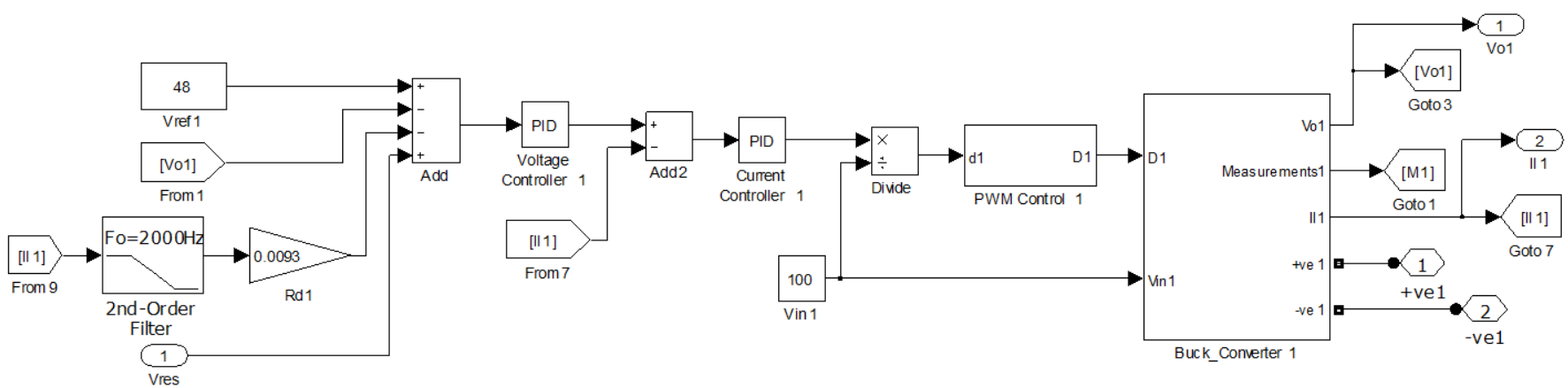

Fig. 7. Cascaded Current and Voltage Control System

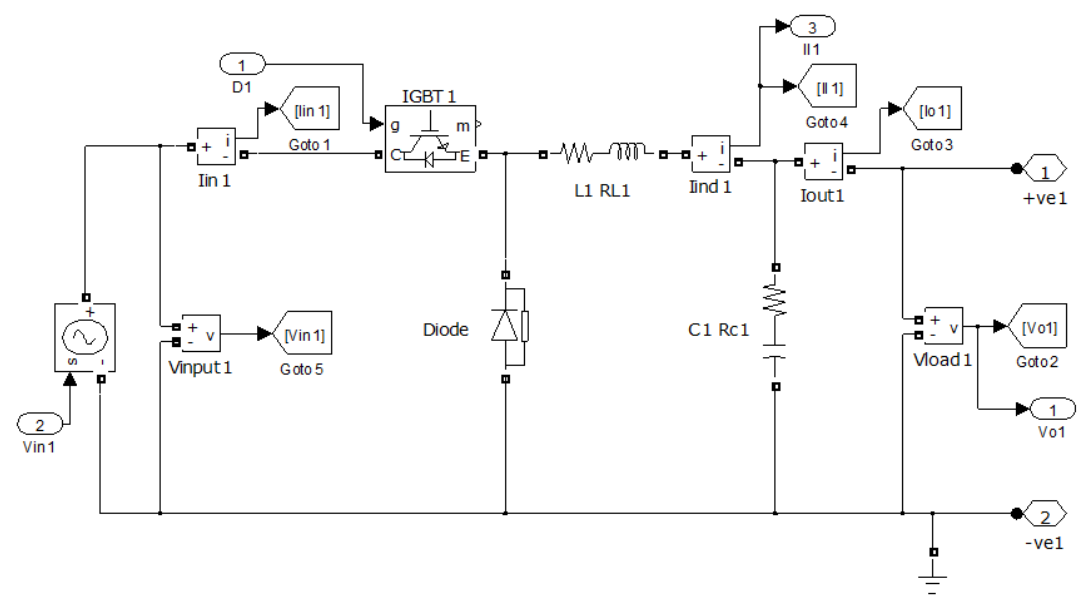

Fig. 8. Buck Converter Modelled in Simulink 


\section{v. Simulation Results}

Figs. 9 and 10 show the results for the simulation which tested the start up of the converters with a common resistive load of $0.4608 \Omega$. Fig. 9 shows the output currents for the two Buck converters $\left(I_{o 1}\right.$ and $I_{o 2}$ ) and the total output current through the resistive load $\left(I_{o}\right)$. Fig. 10 shows the output voltage $\left(V_{o}\right)$. Figs. 11 and 12 show the results for the simulation which tested the performance with a change in load, where the common resistive load was changed to $0.553 \Omega$ at 1 second and changed back to $0.4608 \Omega$ at 3 seconds. Fig. 11 shows the output currents for the two Buck converters and the total output current through the resistive load. Fig. 12 shows the output voltage. The results show the correct operation of the current and voltage control loops as well as the load sharing between the Buck converters with the droop loop. The voltage restoration control loop corrected any output voltage variations caused by the droop loop back to the requested $48 \mathrm{~V}$.



Fig. 9. Output Currents ( $I_{o 1}$ and $I_{o 2}$ - on top of each other)

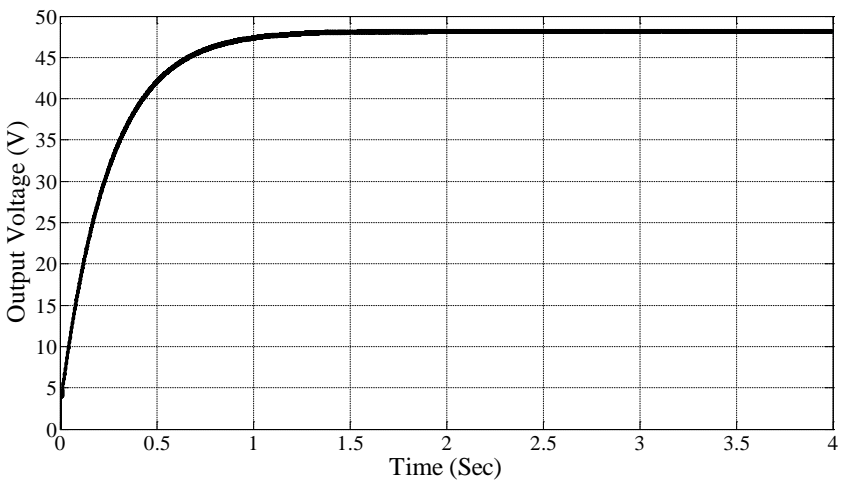

Fig. 10. Output Voltage

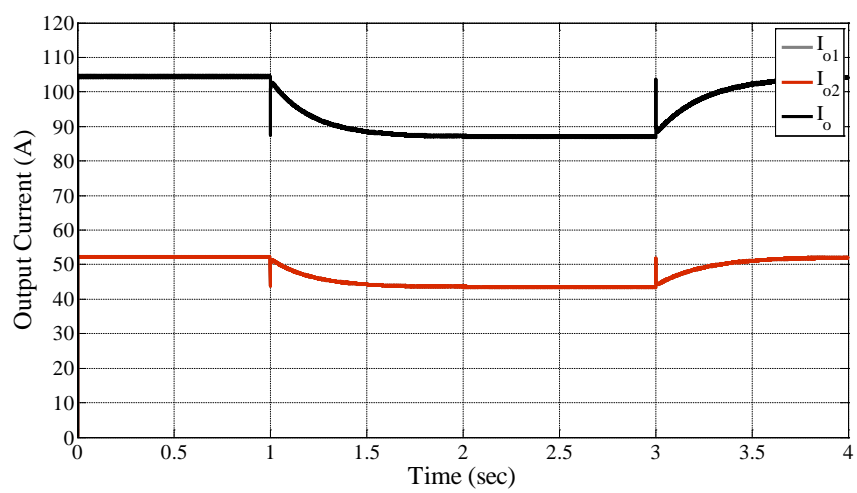

Fig. 11. Output Current with a Load Change ( $I_{o 1}$ and $I_{o 2}$ - on top of each other)

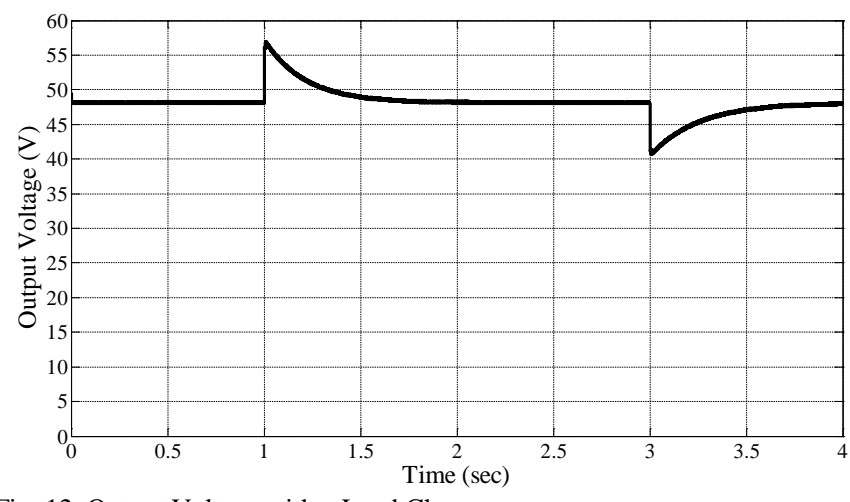

Fig. 12. Output Voltage with a Load Change

\section{vi. Conclusion}

The paper presented the theory, modelling and design of a Buck converter as well as the control system needed to operate multiple paralleled converters sharing a common load in a DC microgrid. To verify the operation of the system, simulations were carried out in Simulink. The obtained results showed the effective paralleling and load sharing of the two Buck converters.

\section{References}

[1] Q. Shafiee, T. Dragicevic, J. C. Vasquez and J. M. Guerrero, “Modeling, Stability Analysis and Active Stabilization of Multiple DC-Microgrid Clusters”, Energycon 2014, Dubrovnik, Croatia, May 2014.

[2] J. M. Guerrero, J. C. Vasquez, J. Matas, L. G. de Vicuna and M. Castilla, "Hierarchical Control of Droop-Controlled AC and DC Microgrids - A General Approach Towards Standardization”, IEEE Transactions on Industrial Electronics, Vol. 58, No. 1, January 2011.

[3] Q. Shafiee, T. Dragicevic, J. C. Vasquez and J. M. Guerrero, "Heirarchical Control for Multiple DC-Microgrids Clusters", IEEE Transactions on Energy Conversion, Vol. 29, No. 4, December 2014.

[4] S. Anand and B. G. Fernandes, "Optimal Voltage Level for DC Microgrids”, 36 ${ }^{\text {th }}$ Annual Conference (IECON 2010), IEEE Industrial Electronics Society, November 2010.

[5] P. Karlsson and J. Svensson, "Voltage Control and Load Sharing in DC Distributed Systems”, European Power Electronics Conference (EPE 2003), Toulouse, France, September 2003.

[6] B. M. Han and H. J. Kim, "Operation Analysis of Coordinated Droop Control for Stand-Alone DC Microgrid”, International Conference on Renewable Energies and Power Quality (ICREPQ'14), Cordoba, Spain, April 2014.

[7] X. Lu, K. Sun, J. M. Guerrero, J. C. Vasquez and L. Huang, "State-ofCharge Balance Using Adaptive Droop Control for Distributed Energy Storage Systems in DC Microgrid Applications”, IEEE Transactions on Industrial Electronics, Vol. 61, No. 6, June 2014.

[8] S. Anand and B. G. Fernandes, "Modified Droop Controller for Paralleling of DC-DC Converters in Standalone DC System”, IET Power Electronics, Vol. 5, Issue 6, February 2012.

[9] Y. H. Huang, C. K. Tse and H. H. C. Lu, "Comparison of Configurations for Parallel DC/DC Converters”, Australasian Universities Power Engineering Conference (AUPEC 2007), December 2007.

[10] R. Zamora and A. K. Srivastava, "Energy Management and Control Algorithms for Integration of Energy Storage Within Microgrid”, $23^{\text {rd }}$ International Symposium on Industrial Electronics (ISIE 2014), June 2014. 
Draft version - Final version on IEEE Xplore

(C) (C) 2016 IEEE. Personal use of this material is permitted. Permission from IEEE must be obtained for all other uses, in any current or future media, including reprinting/republishing this material for advertising or promotional purposes, creating new collective works, for resale or redistribution to servers or lists, or reuse of any copyrighted component of this work in other works. 